\title{
APLIKASI COMMODITY SYSTEM ASSESSMENT METHOD (CSAM) DALAM DISTRIBUSI CABAI ( Capsicum annum L) DARI PETANI DI KECAMATAN PENEBEL SAMPAI PENGECER Application Commodity System Assessment Method in the distribution chili (Capsicum annum L.) of farmers in Penebel District to retailers
}

\author{
I Gusti Ngurah Cahyadi Kresnawan, Amna Hartiati*, I Wy Gd. Sedana Yoga \\ PS Teknologi Industri Pertanian, Fakultas Teknologi Pertanian, Universitas Udayana, Kampus Bukit \\ Jimbaran, Badung, Kode pos : 80361; Telp/Fax : (0361) 701801.
}

Diterima 21September 2018 / Disetujui 28 November 2018

\begin{abstract}
The purpose of this study were (1) to determine the number of chili (Capsicum annum L) distribution lines from farmers in Penebel Subdistrict to the retailers, (2) find out the type of chili postharvest handling from farmers in Penebel District to retailers and find out the impact of losses from farmers in the District Penebel to retailers. The method used in this study is a survey method with the application of a questionnaire Commodity System Assessment Method that is distributed to farmers, collectors, traders, and retailers. The results of the study show that there are 3 distribution channels, namely lane I - retailers, lane II farmers - collectors - retailers, lane III farmers - collectors - traders - retailers. Handling at the farm level includes harvesting, cleaning and sorting, packaging, postharvest handling at the level of collectors, traders and retailers including weighing, cleaning and sorting, packaging and transportation. The impact of the loss of chili postharvest at the farmer level is significant at $10.48 \%$, at the level of collectors in the sorting process is insignificant reaching $2.80 \%$, at the level of large traders in the sorting process is insignificant reaching $2.2 \%$ and at the retail level at the sorting process is significant reaching $6.41 \%$.
\end{abstract}

Keywords: Chili, CSAM and Distribution channel

\begin{abstract}
ABSTRAK
Tujuan penilitian ini adalah untuk mengetahui jumlah jalur distribusi cabai (Capsicum annum L.) dari petani di Kecamatan Penebel sampai ke Pengecer, mengetahui jenis penanganan pascapanen cabai dari petani di Kecamatan Penebel sampai ke Pengecer, mengetahui dampak kehilangan dari petani di Kecamatan Penebel sampai ke Pengecer. Metode yang digunakan dalam penelitian ini adalah metode survei dengan aplikasi Commodity System Assesment Method berupa kusioner yang disebarkan pada petani, pengepul, pedagang dan pengecer.Dalam Pendistribusian cabai, Terdapat 3 jalur distribusi cabai yaitu, jalur1 petani - pengecer, jalur II petani - pengepul - pengecer, jalur III petani - pengepul pedagang besar - pengecer. Penanganan pascapanen di tingkat petani meliputi pemanenan, sortasi dan pembersihan, pengemasan, penanganan pascapanen di tingkat pengepul, pedagang besar dan pengecer meliputi penimbangan, sortasi, pengemasan dan pengangkutan. Dampak kehilangan pascapanen cabai di tingkat petani yaitu pada sortasi signifikan mencapai $10,49 \%$, ditingkat pengepul pada proses sortasi
\end{abstract}

\footnotetext{
*Korespondensi Penulis:

Email: amnahartiati@unud.ac.id
} 
tidak signifikan mencapai $2,80 \%$, di tingkat pedagang besar signifikan yaitu tidak signifikan mencapai $2,2 \%$ dan di tingkat pengecer pada proses sortasi yaitu signifikan mencapai $6,42 \%$.

Kata kunci : Cabai, CSAM dan Jalur distribusi

\section{PENDAHULUAN}

Sektor pertanian berperan penting dalam menunjang perekonomian di Bali. Sektor ini menyumbang $14,64 \%$ dari total PDRB (Pendapatan Domestik Regional Bruto) Bali serta menyediakan lapangan pekerjaan bagi 23,25\% penduduk Bali dalam usia kerja pada tahun 2014. Hal ini menunjukkan bahwa sektor pertanian memiliki peran penting bagi pembangunan di Bali (BPS, 2014). Cabai yang dihasilkan oleh petani di kecamatan Penebel mengalami beberapa jalur distribusi sebelum mencapai ke tangan konsumen seperti pengepul, pedagang besardan pengecer.

Cabai merupakan salah satu komoditas holtikultura yang banyak dibudidayakan oleh petani di Indonesia, karena memiliki harga jual yang tinggi dan memiliki beberapa manfaat kesehatan. Salah satunya berfungsi dalam mengendalikan kanker karena mengandung Lasparaginase dan capcaicin yang berperan sebagai zat anti kanker. Selain itu kandungan vitamin $\mathrm{C}$ yang cukup tinggi pada cabai dapat memenuhi kebutuhan harian setiap orang, namun harus dikonsumsi secukupnya untuk menghindari nyeri lambung (Prajnata, 2001).

Pengawasan mutu dan penanganan cabai yang benar diperlukan agar pada saat siap dipasarkan juga mutu yang baik. Berdasarkan hal tersebut perlu dilakukan penelitian pascapanen cabai untuk mengetahui proses penanganannya menggunakan metode Commodity System Assessment Method (CSAM). CSAM merupakan suatu metode penelitian yang mengkaji komoditas tertentu, memulai dari perencanaan produksi sampai distribusi akhir hingga konsumen, serta mengidentifikasi prioritas permasalahan yang terjadi sepanjang tahapan distribusi. Dengan metode CSAM penanganan pascapanen cabai sejak awal sampai pemasarannya bisa dipantau, dan dapat mengetahui dampak penanganan pascapanen pada setiap jalur distribusi. Penerapan CSAM dan dengan diperkuat rantai distribusi akan dapat diperoleh produk-produk hortikultura bermutu yang mampu bersaing di pasaran.

\section{METODE PENELITIAN}

Penelitian dilaksanakan di Kecamatan Penebel, Kabupaten Tabanan sampai ke Pengecer untuk mengetahui jalur distribusi dan penanganan pascapanen cabai. Metode yang digunakan dalam penelitian ini menggunakan metode survei dengan aplikasi CSAM (Commodity System Assessment Method) dan menggunakan alat survei berupa kuisioner yang disebarkan pada petani, pegepul, pedagang dan pengecer cabai di Kecamatan Kintamani sampai Denpasar. Populasi yang diamati adalah petani, pengepul, pedagang dan pengecer yang terlibat dalam distribusi cabai. Berdasarkan syarat pengambilan sampel, diperlukan data minimal $30 \%$ (Singarimbun dan Effendi, 1989) sehingga sampel penelitian masingmasing adalah $30 \%$ dari seluruh jumlah petani cabai di Kecamatann Penebel serta pengepul, pedagang dan pengecer. Populasi penelitian terdiri dari Sampel petani di Kecamatan Penebel dapat dilihat pada Tabel 1.

Tabel 1.Sampel petani di Kecamatan Penebel

\begin{tabular}{lc}
\hline \multicolumn{1}{c}{$\begin{array}{c}\text { Kecamatan Penebel } \\
\text { (Petani di 4 desa) }\end{array}$} & $\begin{array}{c}\text { Jumlah sampel } \\
\text { Petani }\end{array}$ \\
\hline Kelompok Tani Desa Biaung & 5 orang \\
Kelompok Tani Desa Cacab & 5 orang \\
Kelompok Tani Desa Babahan & 5 orang \\
Kelompok Tani Desa Pemanis & 5 orang \\
\hline
\end{tabular}


a. Pengepul : terdapat 3 pengepul yang mendistribusikan cabai ke konsumen maka seluruh sampel dipakai karena kurang dari 30 unit.

b. Pedagang : terdapat 1 pedagang besar yang mendistribusikan cabai kepengecer maka seluruh sampel dipakai karena kurang dari 30 unit.

c. Pengecer : terdapat7 pengecer yang menjual cabai (Capsicum annum L) maka seluruh sampel dipakai karena kurang dari 30.

\section{Variabel yang diamati}

Penentuan variabel yang diamati dari proses serta jalur distribusi cabai terkait dengan penangan produk adalah sistem penanganan pascapanen dari petani hingga pengecer, identifikasi pelaku dan aktivitas yang dilakukan dalam segmen distribusi, dampak penanganan terhadap kelayakan penekanan atau kehilangan pascapanen, pengumpulan data.

\section{HASIL DAN PEMBAHASAN}

\section{Jalur distribusi cabai dari petani sampai ke pengecer di Kecamatan Penebel Jalur I. Petani $\rightarrow$ Pengecer}

Petani pada jalur I di Kecamatan Penebel menjual cabai langsung ke pengecer di pasar Badung. Petani dan pengecer pasar pada jalur ini berasal dari wilayah desa yang berbeda.

\section{Jalur II. Petani $\rightarrow$ Pengepul $\rightarrow$ Pengecer}

Petani pada jalur II di Kecamatan Penebel menjual cabai kepada pengepul dengan cara pengepul mengambil cabai langsung di lahan petani. Kemudian pengepul menjual cabai ke pengecer di pasar tradisional. Jalur ini menunjukkan bahwa pengepul sebagai pemegang peranan penting untuk memastikan para pedagang pasar tradisional mendapatkan pasokan cabai. Hal ini sesuai dengan pendapat Widiastuti dan Hasanudin (2013) setiap lembaga pemasaran mempunyai peranan penting dalam kegiatan pemasaran.

\section{Jalur III. Petani $\rightarrow$ Pengepul $\rightarrow$ Pedagang besar $\rightarrow$ Pengecer}

Petani pada jalur III di Kecamatan Penebel menjual cabai pada pengepul dengan cara pengepul mengambil langsung ke lahan petani, kemudian pengepul menjual cabai ke Pedagang besar cabai, selanjutnya cabai di beli oleh pengecer dengan cara pengecer mendatangi pedagang besar. Hal ini sesuai dengan pendapat Rum (2011) yang menyatakan bahawa pengecer adalah rantai pemasaran terakhir yang langsung berhadapan dengan konsumen.

Penanganan pascapanen cabai pada jalur distribusi dari petani di Kecamatan Penebel ke pengecer.

Jalur I. Petani ---- Pengecer

Penanganan pascapanen di tingkat petani adalah pemanenan, sortasi, pengemasan, dan pengangkutan. Pemanenan cabai dilakukan saat cabai memasuki usia 120 hari yang bertujuan untuk memetik cabai yang telah siap panen, agar cabai tidak memasuki fase generatif. Sortasi dilakukan dengan cara membuang atau memilih warna cabai akibat terkena penyakit ataupun dimakan hama. Selanjutnya dilakukan pengemasan dengan menggunakan keranjang bambu atau ember, kemudian cabai diangkut menggunakan mobil bak terbuka menuju pengecer.

Penanganan yang dilakukan pada tingkat pengecer adalah sortasi untuk mengetahui ada tidaknya kerusakan pada cabai. Sortasi dilakukan dengan cara mengklompokkan cabai kemudian dilakukan penimbangan dan pengemasan.

\section{Jalur II. Petani ---- Pengepul ---- Pengecer}

Penanganan pascapanen di tingkat petani adalah pemanenan, sortasi, dan pengemasan. Pemanenan cabai dilakukan saat cabai memasuki usia 120 hari yang bertujuan untuk memetik cabai yang telah siap panen, agar cabai tidak memasuki fase generatif. Sortasi dilakukan dengan cara memilih cabai yang 
baik untuk dipanen dan membuang cabai yang rusak atau busuk akibat terkena penyakit ataupun dimakan hama. Selanjutnya dilakukan pengemasan dengan menggunakan keranjang bambu.

Penanganan pascapanen pada pengepul adalah penimbangan, dan pengangkutan. Penimbangan dilakukan untuk mengetahui berat cabai secara keseluruhan yang didapatkan dari hasil panen petani. Penimbangan dilakukan dengan menggunakan timbangan manual. Pada proses pengangkutan cabai yang berada dalam kemasan keranjang bambu diangkut menggunakan mobil bak terbuka menuju pengecer.

Di tingkat pengecer penanganan pascapanen cabai yang dilakukan adalah sortasi yang bertujuan untuk mengetahui ada tidaknya kerusakan pada cabai yang diterima dari pengepul. Tahapan sortasi ini dilakukan dengan cara membuang cabai yang busuk dan mengklompokkan cabai yang berwarna merah dan hijau. Kemudian dilakukan pengemasan dengan keranjang bambu dan karung.

\section{Jalur III. Petani ---- Pengepul ---- Pedagang besar ---- Pengecer}

Penanganan pascapanen di tingkat petani adalah pemanenan, sortasi, dan pengemasan. Pemanenan cabai dilakukan saat cabai memasuki usia 120 hari yang bertujuan untuk memetik cabai yang telah siap panen, agar cabai tidak memasuki fase generatif. Sortasi dilakukan dengan cara memilih cabai yang baik untuk dipanen dan membuang cabai yang rusak atau busuk akibat terkena penyakit ataupun dimakan hama. Selanjutnya dilakukan pengemasan dengan menggunakan keranjang bambu.

Penanganan pascapanen yang dilakukan pada tingkat pengepul adalah penimbangan dan pengangkutan. Penimbangan dilakukan untuk mengetahui berat cabai secara keseluruhan yang diperoleh dari hasil panen petani. Penimbangan dilakukan dengan menggunakan timbangan manual. Pada proses pengangkutan cabai yang berada dalam kemasan keranjang bambu diangkut menggunakan mobil bak terbuka menuju pedagang besar.

Penaganan yang dilakukan pada tingkat pedagang besar adalah penimbangan, sortasi dan pengangkutan. Penimbangan dilakukan untuk mengetahui berat keseluruhan cabai yang diperoleh dari pasokan di pengepul. Penimbangan dilakukan dengan menggunakan timbangan manual. Kemudian dilakukan sortasi dengan cara membuang cabai yang rusak atau yang layu akibat pengiriman. Pengangkutan cabai dalam keranjang bambu yang sudah di timbang diangkut menggunakan mobil bak terbuka menuju ke pengecer.

Penanganan pascapanen cabai ditingkat pengecer adalah sortasi yang bertujuan untuk mengetahui ada tidaknya kerusakan pada cabai yang diterima dari pengepul. Tahapan sortasi ini dilakukan dengan cara membuang cabai yang busuk dan mengklompokkan cabai yang berwarna merah dan hijau. Kemudian dilakukan pengemasan dengan keranjang bambu dan karung.

Rata-rata Hasil Panen, Kehilangan saat Sortasi, Hasil Penjualan, Persentase Penjualan dan Persentase Kehilangan di Tingkat Petani.

Data hasil panen, kehilangan sortasi dan hasil panen bersih di tingkat petani dapat dilihat pada Tabel 1. Hasil panen, kehilangan saat sortasi, dan hasil panen bersih dengan presentase hasil panen bersih cabai mencapai $(90,44 \%)$ dan kehilangan saat sortasi $(10,48 \%)$. Kehilangan saat sortasi cabai terjadi karena mengalami kerusakan seperti cabai yang sudah kuning dan terdapat berlubang pada cabai itu sendiri atau busuk.

\footnotetext{
Rata-rata Hasil Panen, Kehilangan saat Sortasi, Hasil Penjualan, Persentase Penjualan dan Persentase Kehilangan di Tingkat Pengecer.
} 
Data hasil pembelian, kehilangan susut bobot dan penjualan di tingkat pengecer dapat dilihat pada Tabel 2. Hasil pembelian cabai, kehilangan susut bobot, dan penjualan. Presentase rata-rata pejualan produk di tingkat pengecer mencapai $(94,2 \%)$ dan kehilangan susut bobot mencapai $(6,41 \%)$. Kehilangan susut bobot terjadi saat sortasi. Kerusakan yang terjadi separti pelayuan, berubahan warna, dan memar-memar. Kerusakan fisik seperti memar dan luka pada sayur dapat mengakibatkan kerusakan yang lebih serius, yaitu penurunan kualitas sayur secara kimiawi maupun mikrobiologis, sayur yang mengalami luka fisik, selain tampilannya menjadi kurang baik, juga akan memicu terjadinya pembusukan (Qanitah, 2011).

Tabel 1. Hasil panen, kehilangan saat sortasi, dan hasil panen bersih di tingkat petani.

\begin{tabular}{cccc}
\hline Petani & $\begin{array}{c}\text { Hasil } \\
\text { panen } \\
(\mathrm{Kg})\end{array}$ & $\begin{array}{c}\text { Susut } \\
\text { bobot } \\
(\mathrm{Kg})\end{array}$ & $\begin{array}{c}\text { Hasil } \\
\text { panen } \\
\text { bersih } \\
(\mathrm{Kg})\end{array}$ \\
\hline Total & 534 & 56 & 483 \\
\hline Rata-rata & 26,7 & 2,8 & 24,15 \\
\hline Presentase & & $10,48 \%$ & $90,44 \%$ \\
\hline
\end{tabular}

Tabel 2. Hasil pembelian, kehilangan susut bobot,dan penjualan di tingkat pengecer.

\begin{tabular}{cccc}
\hline Pengecer & $\begin{array}{c}\text { Pembelian } \\
(\mathrm{Kg})\end{array}$ & $\begin{array}{c}\text { Susut } \\
\text { bobot } \\
(\mathrm{Kg})\end{array}$ & $\begin{array}{c}\text { Penjualan } \\
(\mathrm{Kg})\end{array}$ \\
\hline Total & 420 & 27 & 396 \\
\hline Rata-rata & 60 & 3,85 & 56,57 \\
\hline Presentase & & $6,41 \%$ & $94,2 \%$ \\
\hline
\end{tabular}

Rata-rata Hasil Panen, Kehilangan saat Sortasi, Hasil Penjualan, Persentase Penjualan dan Persentase Kehilangan di Tingkat Pengepul

Data hasil pembelian, kehilangan susut bobot dan penjualan ditingkat pengepul dapat dilihat pada Tabel 3. Hasil pembelian, kehilangan susut bobot, dan penjualan menunjukan rata- rata penjualan produk cabai di tingkat pengepul mencapai $(97,20 \%)$ dan tingkat kehilangan susut bobot mencapai $(2,80 \%)$. Hal ini disebabkan oleh dalam proses pendistribusian saat cabai berada di petani dan pada saat berada di pengepul sehingga menyebabkan terjadinya laju respirasi pada cabai yang berakibat pada penurunan kadar air dan penurunan berat pada cabai.

Tabel 3. Hasil pembelian, kehilangan susut bobot, dan penjualan di tingkat pengepul.

\begin{tabular}{cccc}
\hline Pengepul & Pembelian $(\mathrm{Kg})$ & Susut bobot $(\mathrm{Kg})$ & $\begin{array}{c}\text { Penjualan } \\
(\mathrm{Kg})\end{array}$ \\
\hline Total & 250 & 7 & 243 \\
\hline Rata-rata & 83,33 & 2,3 & 81 \\
\hline Presentase & & $2,80 \%$ & $97,20 \%$ \\
\hline
\end{tabular}

Rata-rata Hasil Panen, Kehilangan saat Sortasi, Hasil Penjualan, Persentase Penjualan dan Persentase Kehilangan di Tingkat Pedagang besar

Data hasil pembelian, kehilangan susut bobot dan penjualan di tingkat pedagang besar dapat dilihat pada Tabel 4. Hasil pembelian cabai dari pengepul, kehilangan susut bobot, dan penjualan dengan presentase rata-rata penjualan produk di tingkat pedagang besar mencapai $(97,7 \%)$ dan kehilangan susut bobot adalah $(2,2 \%)$. Penyebab kerusakan cabai disebabkan adanya getaran, gesekan dan benturanbenturan mekanis selama proses distribusi dari pengepul menuju pedagang besar. Menurut Susiwi (2009), kerusakan mekanis disebabkan oleh terjadinya benturan antar 
bahan selama pengangkutan (tertindih atau tertekan) maupun terjatuh, sehingga mengalami cacat berupa memar.

\section{Sistem Penanganan Pascapanen Cabai dari Petani Sampai Pengecer}

Tahapan sistem penanganan pascapanen cabai ditiap tingkat distribusi berbeda-beda baik ditingkat petani, pengepul, pedagang, dan pengecer. Sistem penanganan di tingkat petani adalah pemanenan, pembersihan dan sortasi, pengemasan dan pengangkutan, sistem penanganan di tingkat pengepul adalah penimbangan, pembersihan dan sortasi, dan pengangkutan, sistem penanganan di tingkat pengecer adalah penimbangan, pembesihan dan sortasi serta pengankutan. Sistem penanganan pascapanen dapat dilihat pada tabel 5 .

Tabel 4. Hasil pembelian, kehilangan susut bobot, dan penjualan di tingkat pedagang besar.

\begin{tabular}{cccc}
\hline $\begin{array}{c}\text { Pedagang } \\
\text { Besar }\end{array}$ & Pembelian $(\mathrm{Kg})$ & $\begin{array}{c}\text { Kehilangan Susut } \\
\text { Bobot }(\mathrm{Kg})\end{array}$ & $\begin{array}{c}\text { Penjualan } \\
(\mathrm{Kg})\end{array}$ \\
\hline Total & 450 & 10 & 440 \\
\hline Rata-rata & 450 & 10 & 440 \\
\hline Presentase & & $2,2 \%$ & $97,7 \%$ \\
\hline
\end{tabular}

Tabel 5. Sistem penanganan Pascapanen cabai dari Petani sampai Pengecer.

\begin{tabular}{|c|c|c|c|c|c|c|c|c|}
\hline \multirow{2}{*}{$\begin{array}{l}\text { Tahapan } \\
\text { sistem } \\
\text { penanganan }\end{array}$} & \multicolumn{4}{|c|}{ Symbol } & \multicolumn{4}{|c|}{ Informasi Tambahan } \\
\hline & 017 & \begin{tabular}{l|l}
$T$ & $I$
\end{tabular} & \begin{tabular}{l|l}
$\mathrm{I}$ & $\mathrm{I}$ \\
$\mathrm{n}$
\end{tabular} & $\mathrm{s}$ & Temperatur & Jarak & Waktu & Pengamatan \\
\hline $\begin{array}{l}\text { Tingkat } \\
\text { Petani } \\
\text { Pemanenan }\end{array}$ & a & & & & $18-19^{\circ} \mathrm{C}$ & $\begin{array}{l} \pm 5 \\
\mathrm{~km}\end{array}$ & $\begin{array}{c}\text { Jam } \\
08.00- \\
10.00 \\
\end{array}$ & $\begin{array}{l}\text { Petani memetik cabai yang sudah cukup } \\
\text { umur atau siap dipanen dengan tangan } \\
\text { (manual) }\end{array}$ \\
\hline $\begin{array}{l}\text { Pembersihan } \\
\text { dan Sortasi }\end{array}$ & & & & & $18-19^{\circ} \mathrm{C}$ & $\begin{array}{c} \pm 2 \\
\mathrm{~m}\end{array}$ & $\begin{array}{c}\mathrm{Jam} \\
10.00- \\
11.00\end{array}$ & $\begin{array}{l}\text { Petani memisahkan cabai yang rusak } \\
\text { dan terkena penyakit }\end{array}$ \\
\hline Pengemasan & Q & & & & $18-19^{\circ} \mathrm{C}$ & $\begin{array}{c} \pm 2 \\
m\end{array}$ & $\begin{array}{c}\mathrm{Jam} \\
11.00- \\
12.00\end{array}$ & $\begin{array}{l}\text { Pengemasan dilakukan dengan } \\
\text { menggunakan karung atau keranjang }\end{array}$ \\
\hline Pengangkutan & - & & & & $18-19^{\circ} \mathrm{C}$ & $\begin{array}{c} \pm 10 \\
\mathrm{~m}\end{array}$ & $\begin{array}{l}\text { Jam } \\
06.00- \\
07.00\end{array}$ & $\begin{array}{l}\text { Pengangkutan dilakukan dengan mobil } \\
\text { bak terbuka }\end{array}$ \\
\hline $\begin{array}{l}\text { Tingkat } \\
\text { Pengepul } \\
\text { Penimbangan }\end{array}$ & & & & & $21-24^{\circ} \mathrm{C}$ & $\begin{array}{c} \pm 1 \\
\mathrm{~m}\end{array}$ & $\begin{array}{l}06.00- \\
07.00 \\
\text { sore }\end{array}$ & Menimbang caba \\
\hline $\begin{array}{l}\text { Pembersihan } \\
\text { dan sortasi }\end{array}$ & & & & & $21-24^{\circ} \mathrm{C}$ & $\begin{array}{c} \pm 25 \\
\mathrm{~m}\end{array}$ & $\begin{array}{c}08.00- \\
11.00 \\
\text { pagi }\end{array}$ & $\begin{array}{l}\text { Memisahkan cabai yang baik dan rusak, } \\
\text { kemudian dibedakan menurut warna dan } \\
\text { ukuran. }\end{array}$ \\
\hline Pengangkutan & & & & & $21-24^{\circ} \mathrm{C}$ & $\begin{array}{l} \pm 15 \\
\mathrm{~km}\end{array}$ & $\begin{array}{l}05.00 \\
\text { pagi }\end{array}$ & $\begin{array}{l}\text { Pengangkutan menuju pengecer } \\
\text { dilakukan dengan mobil bak terbuka }\end{array}$ \\
\hline $\begin{array}{l}\text { Tingkat } \\
\text { Pengecer } \\
\text { Penimbangan }\end{array}$ & & & & & $26-28^{\circ} \mathrm{C}$ & $\begin{array}{c} \pm 1 \\
\mathrm{~m}\end{array}$ & $\begin{array}{c}05.00 \\
\text { pagi }\end{array}$ & Menimbang cabai yang akan dibeli \\
\hline $\begin{array}{l}\text { Pembersihan } \\
\text { dan sortasi }\end{array}$ & & & & & $26-28^{\circ} \mathrm{C}$ & $\begin{array}{c} \pm 10 \\
\mathrm{~m}\end{array}$ & $\begin{array}{l}05.00- \\
06.00 \\
\text { pagi }\end{array}$ & $\begin{array}{l}\text { Memisahkan cabai yang baik dan rusak, } \\
\text { kemudian dibedakan menurut warna dan } \\
\text { ukuran. }\end{array}$ \\
\hline Pengangkutan & & 0 & & & $26-28^{\circ} \mathrm{C}$ & $\begin{array}{l} \pm 15 \\
\mathrm{~km}\end{array}$ & $\begin{array}{c}07.00 \\
\text { pagi }\end{array}$ & $\begin{array}{l}\text { Pengangkutan dilakukan dengan mobil } \\
\text { bak terbuka }\end{array}$ \\
\hline
\end{tabular}


Identifikasi Faktor Penanganan Pascapanen di Tingkat Petani, Pengepul, Pedagang dan Pengecer

Faktor-faktor yang teridentifikasi pada penanganan pascapanen di tingkat petani adalah pemanenan, pembersihan dan sortasi, pengemasan dan pengangkutan. Faktorfaktor yang teridentifikasi dalam penanganan pascapanen di tingkat pengepul adalah penimbangan, pembersihan, sortasi, penyimpanan, pengemasan dan pegangkutan dan faktor-faktor yang teridentifikasi pada penanganan pascapanen di tingkat pengecer adalah pengangkutan ,pembersihan, sortasi dan pengangkutan. Identifikasi Faktor penanganan dapat dilihat pada Tabel 6 .

Tabel 6. Identifikasi pelaku penanganan pascapanen dan aktifitas yang dilakukan.

\begin{tabular}{|c|c|c|c|c|c|c|}
\hline \begin{tabular}{|l|} 
Tahapan \\
Penanganan \\
\end{tabular} & $\begin{array}{c}\text { Siapa } \\
\text { Pelakunya }\end{array}$ & $\begin{array}{l}\text { Apa yang } \\
\text { dilakukan }\end{array}$ & $\begin{array}{c}\text { Bagaimana } \\
\text { melakukannya }\end{array}$ & $\begin{array}{c}\text { Kapan } \\
\text { dilakukan }\end{array}$ & $\begin{array}{r}\text { Mengapa } \\
\text { dilakukan }\end{array}$ & $\begin{array}{c}\text { Dimana } \\
\text { dilakukan }\end{array}$ \\
\hline \begin{tabular}{|l|} 
A. Tingkat \\
Petani \\
1. Pemanenan
\end{tabular} & Petani & $\begin{array}{l}\text { Memetik } \\
\text { cabai yang } \\
\text { sudah siap } \\
\text { dipanen. }\end{array}$ & $\begin{array}{l}\text { Cabai dipetik } \\
\text { manual dengan } \\
\text { tangan }\end{array}$ & $\begin{array}{l}120 \text { hari } \\
\text { setelah } \\
\text { penanaman, } \\
\text { pemanenan } \\
\text { dilakukan } \\
\text { pada pagi } \\
\text { atau sore } \\
\text { hari. }\end{array}$ & $\begin{array}{l}\text { Untuk } \\
\text { memetik cabai } \\
\text { yang telah siap } \\
\text { panen, agar } \\
\text { buah tidak } \\
\text { memasuki fase } \\
\text { generatif. }\end{array}$ & $\begin{array}{l}\text { Di kebun } \\
\text { cabai. }\end{array}$ \\
\hline 2. Sortasi & Petani & $\begin{array}{l}\text { Membuang } \\
\text { cabai sudah } \\
\text { menguning, } \\
\text { busuk, } \\
\text { terserang } \\
\text { penyakit } \\
\text { atau } \\
\text { berlubang. }\end{array}$ & $\begin{array}{l}\text { Memisahkan } \\
\text { cabai yang } \\
\text { menguning, } \\
\text { busuk, terserang } \\
\text { penyakit atau } \\
\text { berlubang. }\end{array}$ & $\begin{array}{l}\text { Setelah } \\
\text { proses } \\
\text { pemanenan } \\
\text { cabai. }\end{array}$ & $\begin{array}{l}\text { Untuk } \\
\text { memperoleh } \\
\text { cabai yang } \\
\text { baik. }\end{array}$ & $\begin{array}{l}\text { Di kebun } \\
\text { cabai }\end{array}$ \\
\hline \begin{tabular}{|l}
3. \\
Pengemasan
\end{tabular} & Petani & $\begin{array}{l}\text { Mengemas } \\
\text { cabai } \\
\text { dengan } \\
\text { keranjang } \\
\text { bambu. }\end{array}$ & $\begin{array}{l}\text { Mengelompokkan } \\
\text { cabai } \\
\text { (merah/hijau) } \\
\text { kedalam } \\
\text { keranjang bambu } \\
\text { atau ember. }\end{array}$ & $\begin{array}{l}\text { Setelah } \\
\text { proses } \\
\text { pembersihan } \\
\text { dan sortasi }\end{array}$ & $\begin{array}{l}\text { Untuk } \\
\text { mempermudah } \\
\text { pengiriman } \\
\text { cabai }\end{array}$ & $\begin{array}{l}\text { Di kebun } \\
\text { cabai }\end{array}$ \\
\hline \begin{tabular}{|l|} 
B. Tingkat \\
Pengepul \\
1. \\
Penimbangan
\end{tabular} & Pengepul & $\begin{array}{l}\text { Menimbang } \\
\text { cabai yang } \\
\text { sudah di } \\
\text { angkut dari } \\
\text { petani ke } \\
\text { pengepul }\end{array}$ & $\begin{array}{l}\text { cabai ditimbang } \\
\text { dengan } \\
\text { menggunakan } \\
\text { timbangan } \\
\text { manual }\end{array}$ & $\begin{array}{l}\text { Setelah } \\
\text { cabai tiba di } \\
\text { pengepul. }\end{array}$ & $\begin{array}{l}\text { Untuk } \\
\text { mengetahui } \\
\text { berat cabai } \\
\text { dari hasil } \\
\text { panen petani }\end{array}$ & $\begin{array}{l}\text { Di rumah } \\
\text { pengepul }\end{array}$ \\
\hline \begin{tabular}{|l|}
2. \\
Pengangkutan
\end{tabular} & Pengepul & $\begin{array}{l}\text { Mengangkut } \\
\text { cabai dari } \\
\text { pengepul } \\
\text { sampai ke } \\
\text { Pedagang }\end{array}$ & $\begin{array}{l}\text { Cabai yang } \\
\text { sudah ditimbang } \\
\text { diangkut dengan } \\
\text { mobil bak terbuka }\end{array}$ & $\begin{array}{l}\text { Setelah } \\
\text { cabai } \\
\text { ditimbang } \\
\text { dan siap } \\
\text { untuk } \\
\end{array}$ & $\begin{array}{l}\text { Untuk } \\
\text { mengangkut } \\
\text { cabai dari } \\
\text { pengepul ke } \\
\text { Pedagang }\end{array}$ & $\begin{array}{l}\text { Dari } \\
\text { pengepul } \\
\text { ke } \\
\text { Pedagang } \\
\text { besar }\end{array}$ \\
\hline
\end{tabular}




\section{Dampak Penanganan Terhadap Pascapanen Cabai}

Tabel 7. Dampak Penanganan Pascapanen Cabai Berdasarkan Tingkat Kehilangan Pascapanen yang Tidak Signifikan, Signifikan dan Sangat Signifikan.

\begin{tabular}{|c|c|c|}
\hline & $\begin{array}{c}\text { Tidak } \\
\text { signifikan }\end{array}$ & Signifikan Sangat signifikan \\
\hline \multicolumn{3}{|l|}{ A. Tingkat Petani } \\
\hline Panen & $\sqrt{ }$ & \\
\hline Pengemasan & $\sqrt{ }$ & \\
\hline Pembersihan dan sortasi & & $\sqrt{ }(10,48 \%)$ \\
\hline Pengangkutan & $\sqrt{ }$ & \\
\hline \multicolumn{3}{|l|}{ B. Tingkat Pengepul } \\
\hline Penimbangan & $\sqrt{ }$ & \\
\hline Pembersihan dan sortasi & $\sqrt{ }(2,80 \%)$ & \\
\hline Pengangkutan & $\sqrt{ }$ & \\
\hline \multicolumn{3}{|l|}{ C. Tingkat Pedagang } \\
\hline Penimbangan & $\sqrt{ }$ & \\
\hline Pembersihan dan sortasi & $\sqrt{ }(2,20 \%)$ & \\
\hline Pengangkutan & $\sqrt{ }$ & \\
\hline \multicolumn{3}{|l|}{ D. Pengecer } \\
\hline Penimbangan & $\sqrt{ }$ & \\
\hline Pembersihan dan sortasi & & $\sqrt{ }(6,41 \%)$ \\
\hline Pengangkutan & $\sqrt{ }$ & \\
\hline Keterangan: Tidak signifikan & $:<5 \%$ & \\
\hline Signifikan & $: 5-30 \%$ & \\
\hline Sangat signifikan & $:>30 \%(\mathrm{~L}$ & Gra, 1999). \\
\hline
\end{tabular}

\section{Dampak Penanganan di Tingkat Pengepul}

Dampak pembersihan dan sortasi terhadap kehilangan cabai adalah 2,80\%. Hal ini disebabkan karena jarak tempuh penerimaan cabai dari petani ke pengepul yang dilalui tidak jauh sehingga kerusakan akibat dampak proses distribisi hanya sedikit.

\section{Dampak Penanganan di Tingkat pengecer}

Dampak sortasi terhadap kehilangan cabai adalah signifikan yaitu $6,41 \%$. Kerusakan fisik yang terjadi karena adanya benturan,gesekan, serta tumpukan-tumpukan selama proses distribusi di tingkat pengepul. Sayuran yang mengalami kerusakan fisik, selain tampilannya menjadi kurang baik juga akan memicu terjadinya pembusukan (Qanytah, 2011)

\footnotetext{
Dampak Penanganan di Tingkat Pedagang besar
}

Dampak pembersihan dan sortasi merah adalah tidak signifikan yaitu 2,20\%. Hal ini disebabkan karena jumlah cabai pada distribusi di tingkat pedagang hanya sedikit, sehingga kerusakan-kerusakan berupa adanya benturan, gesekan, serta tumpukantumpukan selama proses distribusi di tingkat pedagang saat pengangkutan hanya sedikit. Kerusakan ini dapat terjadi karena adanya benturan antar bahan selama pengangkutan (tertindih/tertekan) maupun terjatuh, sehingga mengalami cacat berupa memar (Susiwi, 2009).

\section{KESIMPULAN}

\section{Kesimpulan}

Berdasarkan hasil penelitian yang telah dilakukan maka dapat disimpulkan beberapa hal sebagai berikut : 
Terdapat 3 jalur distribusi cabai dari petani ke pengecer di Kecamatan Penebel, yaitu jalur I (Petani $\rightarrow$ Pengecer), jalur II (Petani $\rightarrow$ Pengepul $\rightarrow$ Pengecer), jalur III (Petani $\rightarrow$ Pengepul $\rightarrow$ Pedagang besar $\rightarrow$ Pengecer).

Faktor-faktor yang teridentifikasi dalam penanganan pascapanen cabai yaitu (a) faktor penanganan di tingkat petani adalah pemanenan, pembersihan dan sortasi, pengemasan dan pengangkutan, (b)faktor Penanganan pascapanen di tingkat pengepul adalah pembersihan dan sortasi, penimbangan, dan pengangkutan, (c) faktor penanganan pada tingkat pedagang adalah Pembersihan dan sortasi, penimbangan dan pengangkutan, (d) faktor penanganan pascapanen di tingkat pengecer adalah penimbangan, pembersihan dan sortasi, pengankutan.Dampak penanganan selama tingkat petani yaitu pada pembersihan dan sortasi signifikan mencapai $10,48 \%$. Pada tingkat pengepul yaitu pada pembersihan dan sortasi tidak signifikan yaitu 2,80\%. Pada tingkat pengecer yaitu pembersihan dan sortasi signifikat yaitu $6,41 \%$. Pada tingkat pedagang yaitu pembersihan dan sortasi tidak signifikan yaitu $2,2 \%$.

\section{Saran}

Adapun saran yang dapat diberikan berdasarkan hasil penelitian yang telah dilakukan adalah perlu dilakukan perbaikanperbaikan penanganan pascapanen pada tiap tingkat terutama pada penanganan pascapanen dan perbaikan penyimpanan, transportasi, distribusi, dan pemasaran cabai agar menghasilkan produk hortikultur yang baik. Serta memberikan penjelasan dan arahan pada pelaku penanganan pasca panen sesuai dengan cara-cara penanganan yang baik.

\section{DAFTAR PUSTAKA}

Anonimus. 2014. Bali dalam Angka 2013. Badan Pusat Statistik Provinsi Bali. https://bali.bps.go.id/publication/2013/09/ 20/e4f2b2312d8d1fe08221b05b/balidalam-angka-2013.html

Anonimus. 2015. Balai Penyuluhan Pertanian Perikanan dan Kehutanan Kecamatan Penebel, Kabupaten Tabanan.

BPS Provinsi Bali, Denpasar. 2014. Penduduk Provinsi Bali (Tabel \& Grafik Dinamis).

Budiastra, IG, IGAL, Triani dan A, Hartiati. 2017. Aplikasi Commodity System Assessment Method (CSAM) dalam distribusi kubis dari petani ke pengecer di kecamatan Penebel. ISSN : 2503-488X, Vol 5, No5, Hal 12-20.

Harsojuwono, B., A., 2008. Pentingnya Penerapan Commodity System Assessment Method (CSAM) Pada Penanganan Dan Distribusi Produk Hortikultura. Orasi Ilmiah Guru Besar. UNUD, Badung.

La Graa, 1999. A Commodity System Assessment Methodology for Problem and project Identification. Postharvest Institute for Parishable, College of Agriculture. University of Idaho, Moscow.

Qanytah dan I. Ambarsari, 2011, Efisiensi penggunaan kemasan kardus distribusi Mangga Arumanis. Jurnal pengkajian dan pengembangan Teknologi Pertanian. Volume 30 November 1. Balai Besar P2PT Bogor. Bogor.

Rum, M. 2011. Analisis margin pemasaran dan sensitifitas cabai besar di kabupaten Malang. Jurnal Embryo, 8 (2).

Susiwi, S, 2009. Kerusakan pangan. Skripsi tidak dipublikasikan. Jurusan Pendidikan Kimia. Universitas Pendidikan Indonesia, Jakarta.

Yanti, NPR, IGAL, Triani dan IWGS, Yoga. 2016. Analisis Ekonomi dan Penanganan Pascapanen pada jalur distribusi Selada 
Vol. 6, No.4, Desember 2018.

dari Desa Candikuning, Kec. Baturiti sampai Kota Denpasar. Jurnal Rekayasa
Aplikasi Commodity System Assessment Method...

dan Manajemen Agroindustri. ISSN:

2503-488X, Vol 4, No4, Hal 24-32 